\title{
A COMPUTERIZED RISK EVALUATION MODEL FOR PUBLIC- PRIVATE PARTNERSHIP (PPP) PROJECTS AND ITS APPLICATION
}

\author{
Yelin XU ${ }^{1}$, Yujie LU ${ }^{2} \bowtie$, Albert P. C. CHAN ${ }^{3}$, Miroslaw J. SKIBNIEWSKI ${ }^{4}$ \\ and John F. Y. YEUNG 5 \\ ${ }^{1}$ Department of Engineering Management, Zhejiang Sci-tech University, Hangzhou, China \\ E-mail: xuyelin2007@yahoo.com.cn \\ ${ }^{2}$ School of Economics and Management, Tongji University, Shanghai 200092, China and \\ Department of Civil \& Environmental Engineering, University of Maryland, College Park, \\ Maryland 20742, USA \\ E-mail:lyj0415@gmail.com; luyj@umd.edu \\ ${ }^{3}$ Department of Building and Real Estate, The Hong Kong Polytechnic University, Hung Hom, \\ Kowloon, Hong Kong, China \\ E-mail:bsachan@inet.polyu.edu.hk \\ ${ }^{4}$ Department of Civil and Environmental Engineering, University of Maryland, College Park, \\ 20742, USA \\ E-mail:mirek@umd.edu \\ ${ }^{5}$ College of International Education, School of Continuing Education, Hong Kong Baptist Uni- \\ versity, Hong Kong, China \\ E-mail: jfyyeung@hkbu.edu.hk
}

Received 7 October 2011; accepted 13 December 2011

\begin{abstract}
PPP projects usually involve more risks than other traditional procurement models because of their complexity. This paper presents the third stage of a funded study, which aims to develop a practical and computerized risk evaluation model for PPP projects. In the first and second stages, a risk hierarchal structure composed of 17 weighted risk factors is developed to describe risk profiles of PPP projects. The weightings and membership functions for risk factors are established using the Delphi survey technique and Fuzzy Set Theory. The risk evaluation model is then developed using a fuzzy synthetic evaluation approach. In the third stage, an automated decision support tool based on the risk evaluation model is designed for PPP practitioners by using Visual Basic for Application (VBA). The computerized tool can not only assist PPP participants to assess a PPP project's overall risk level for auxiliary investment decision, but can also help practitioners to identify the most risky areas of a PPP project for effective risk response. To demonstrate the applicability of the computerized model, an illustrative case is finally provided.
\end{abstract}

KEYWORDS: Public Private Partnerships (PPP); Risk evaluation; Risk management; Fuzzy; Decision support

\section{INTRODUCTION}

Since the reform and opening of the national economy in 1978, China has entered into a rapid urbanization period. The United
Nations forecasted that the percentage of the urban population in the PRC would increase from $44.94 \%$ in 2007 to $57 \%$ in 2025 (China Statistical Yearbook, 2008; Chan et al., 2010). As the backbone of the economy, infrastructure 
development is regard as the core component to alleviate the negative impact of unorganized urban growth and China's on-going economic development. "Public-Private Partnership (PPP) financing modalities, with the capability of providing funding and efficient management, have been identified as innovative tools for financing major infrastructure projects in China" (Asian Development Bank, 2005; Chan et al., 2010). However, due to the increasing complexity and extension of the disciplines, multi-public agencies and private sectors involved, existing PPP projects are plagued by risks and often have suffered poor performance in terms of cost overrun and schedule delay (Zeng et al., 2007; Tah and Carr, 2000; Xenidis and Angelides, 2005). The larger the scale and the longer the concession period of a PPP project, the greater the possibility and severity of risks; at the same time, the degree of uncertainty is also harder to evaluate (Warszawski and Sacks, 2004). Thus, an effective risk evaluation model for PPP projects is necessary to increase the chance of project success (Skorupka, 2008).

A substantial number of studies have been devoted to seeking appropriate approaches to facilitate risk evaluation. A number of methods have been adopted to design mathematical models in the project risk management field, including system dynamics (Nasirzadeh et al., 2008), fuzzy set (Tah and Carr, 2000), analytic hierarchy process (Zayed et al., 2008), Monte Carlo simulation (Winter, 1999), neural networks (Jablonowski, 1994), event tree (Ezell et al., 2000), and so on. Forbes et al. (2008) stated that there are a total of 36 different methods available to identify and evaluate risks. However, only a handful of these are utilized as industrial practitioners lack the confidence in using the techniques (Forbes et al., 2008). Moreover, relevant data needed for risk evaluation is also usually difficult to obtain or does not exist in the construction industry (Warszawski and Sacks, 2004; Choi and Mahade- van, 2008). The evaluation of risk level for a specific risk factor or project, based on industrial practitioners' experience and intuition, is a complex process shrouded in uncertainty and vagueness (Tah and Carr, 2000). As a result, risk evaluation is currently often limited to simple sensitivity analyses (Warszawski and Sacks, 2004). On the other hand, various risk factors or indicators are usually adopted to comprehensively evaluate the risk level of a specific PPP project, which result in complicated calculations. It is therefore vital to design a computerized risk evaluation model to ensure the accuracy of the mathematical calculation process.

This paper reports the third stage of a funded research study, which aims at developing a risk evaluation model for PPP projects in China. In this stage, an automated decision support tool based on the risk evaluation model using Visual Basic for Application (VBA) was developed. It will enable private investors or bankers to select more suitable PPP projects through risk evaluation more efficiently and can also help PPP practitioners identify the most risky areas in a PPP project, thus allowing them to make more effective response. In addition, although the development of this risk evaluation model is primarily designed for the PPP practices in China, the research method could be replicated to other countries to produce similar models for risk management.

\section{RESEARCH METHODS}

The research methods employed in this study encompass literature review, a tworound Delphi survey for data collection, factor analysis, fuzzy set theory, and fuzzy synthetic evaluation for data analysis. The general framework is shown in Figure 1. A total of eight steps are conducted to establish the computerized tool for the risk evaluation of PPP projects. 

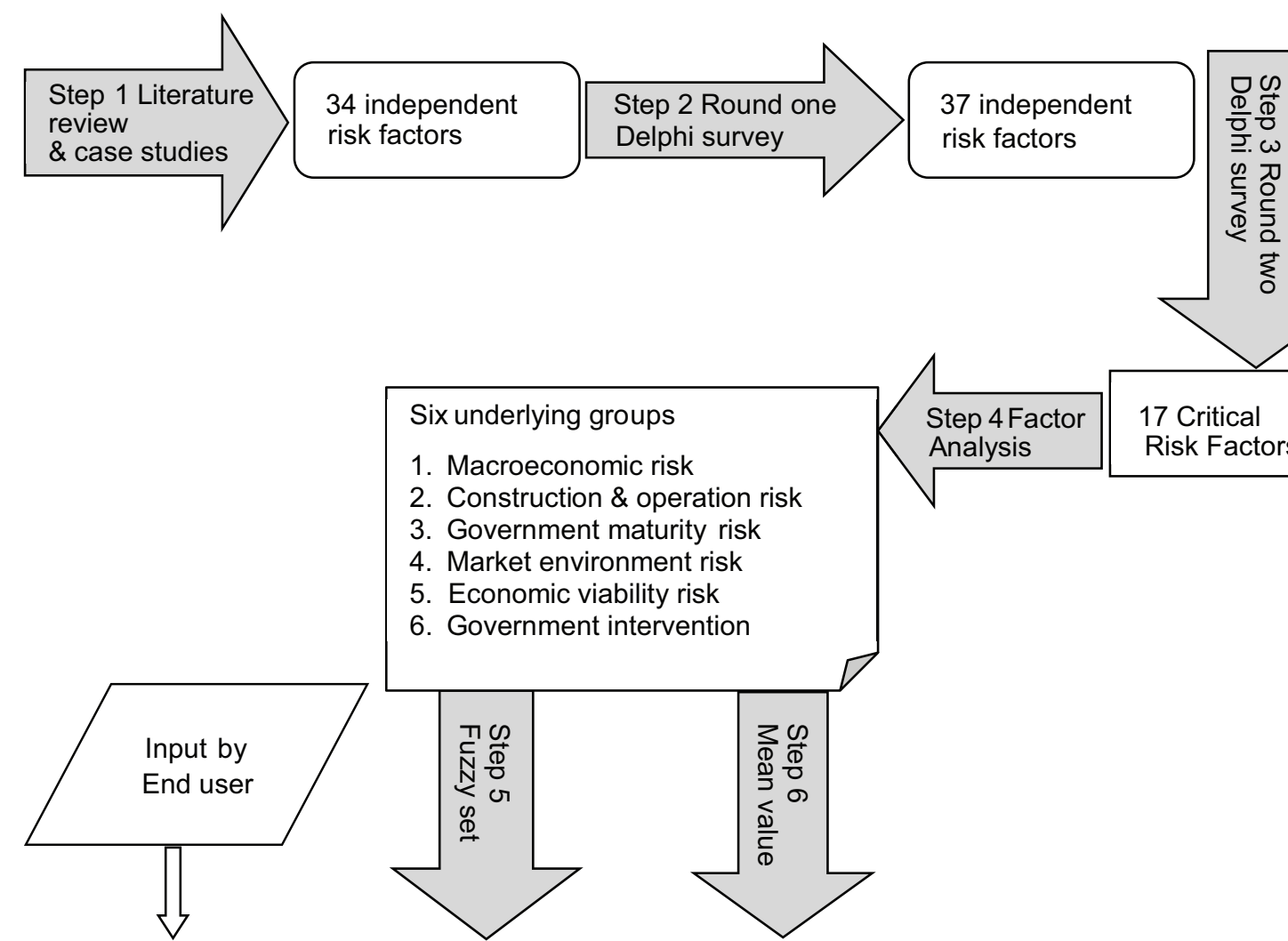

Membership functions of evaluation indicators (Part two)

\section{Six underlying groups}

1. Macroeconomic risk

2. Construction \& operation risk

3. Government maturity risk

4. Market environment risk

5. Economic viability risk

6. Government intervention

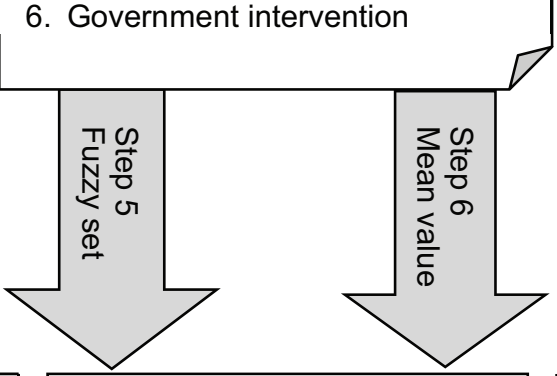

Membership functions of evaluation indicators (Part one)
Weightings of

evaluation indicators

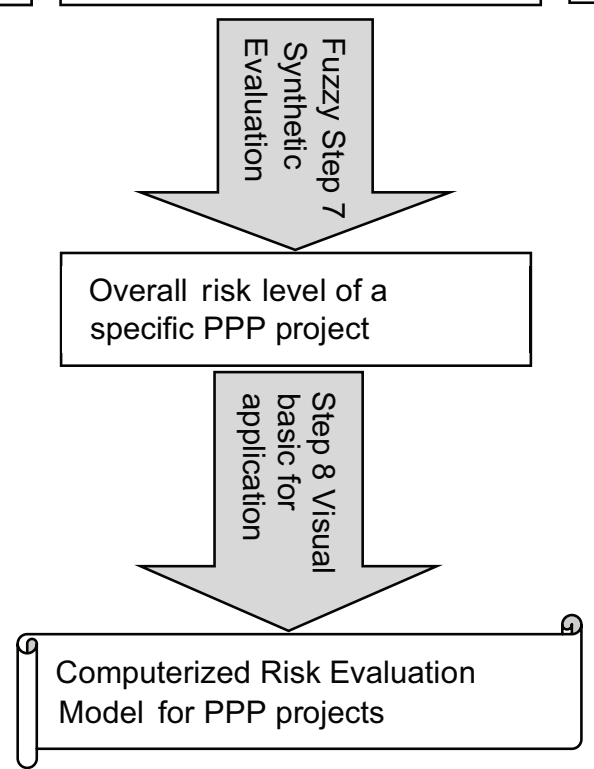

Figure 1. Framework of developing a computerized risk evaluation model for PPP projects 


\subsection{Data collection}

Literature review was first conducted to identify risk factors of PPP projects. A consolidated list of 34 potential key risks associated with PPP projects pertaining to China was identified. Detailed risk factors please refer to $\mathrm{Xu}$ et al. (2010). Based on this list, a two-round Delphi questionnaire survey was designed and conducted. In the first round, the questionnaire was send to a total of 580 experts nationwide and 105 experts participated in. The respondents were requested to: (1) assign an estimated probability of occurrence based on a 5 -point scale (where $1=$ very low and $5=$ almost certain to occur); (2) estimate the severity of the risk on a scale of 1 to 5 (where $1=$ no serious influence on the project and $5=$ catastrophic, where the project would be aborted); and add any new additional risk factors which were not included. After the first round of Delphi survey, not only was the perception of the relative importance of each risk factor acquired, but three new risk factors were also added to the initial risk register including (1) concessionaire change; (2) subjective project evaluation method; and (3) insufficient project finance supervision. Then, in Round 2 of the Delphi survey, the 105 respondents were provided with the consolidated results obtained from Round 1 and were invited to reconsider their scores to see if they would like to adjust their original choices, meanwhile assess the three new risk factors. A total of 93 experts completed the second round of the Delphi questionnaire representing a success rate of $88.6 \%$. A list of general information about the Delphi experts of Round 2 is shown in Table 1. These experts represent a wide spectrum of construction professionals in China and provide a balanced view for the Delphi study. 37.6\% of the respondents were from the private sector (corporation), $14.0 \%$ were from the public sector (government sector), and the remaining respondents mainly consisted of researchers and academics. Furthermore, nearly $80 \%$ of the respondents have more than 5 years of industrial experience. Most of the respondents had been involved with more than one PPP project. Sufficient work experience and relevant organizations of the selected experts ensure the validity of this Delphi study.

Table 1. General Information about the Delphi survey respondents (Round 2)

1) Role of survey respondents

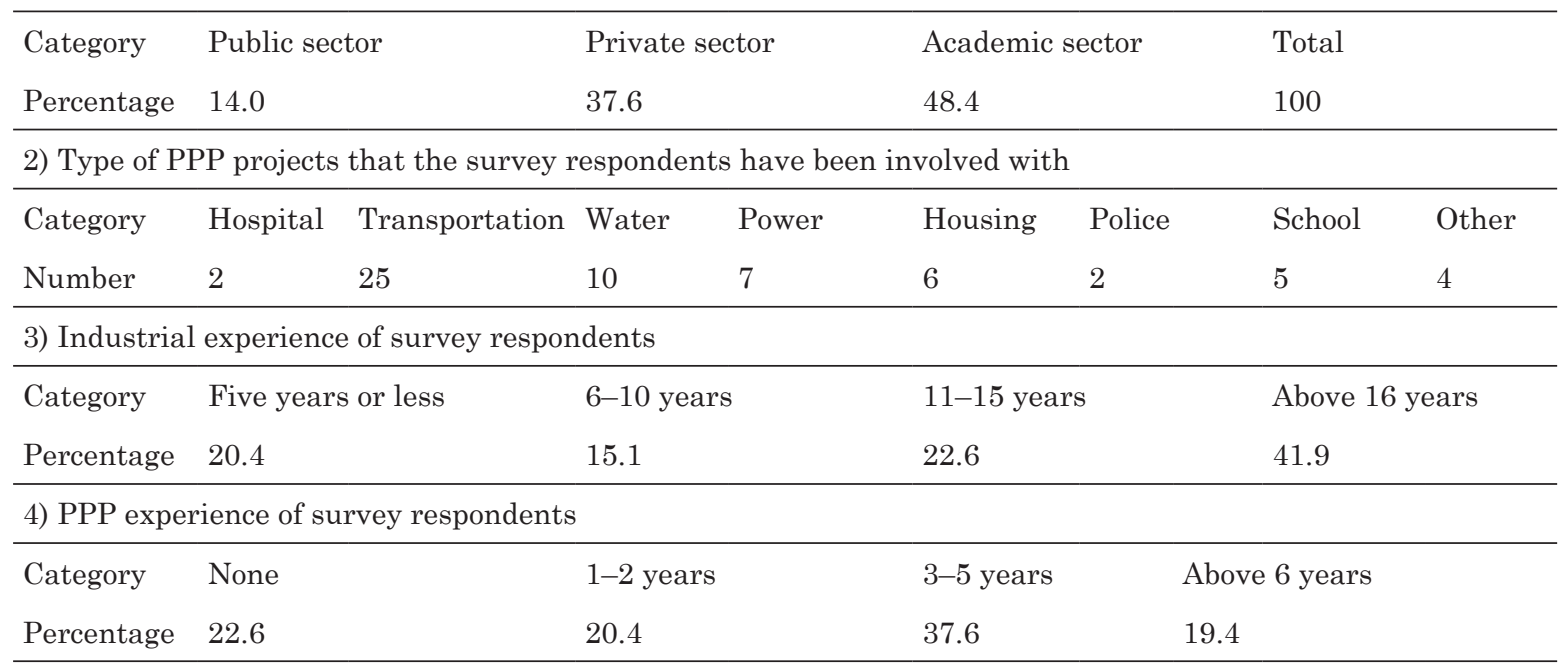




\subsection{Data analysis}

Three mathematical tools, including Factor Analysis (FA), Fuzzy Set (FS), and Fuzzy Synthetic Evaluation (FSE), were used to analyze data collected from the two rounds of Delphi survey. FA is a conventional mathematical technique typically adopted for condensing of large number of variables into fewer groupings (Norusis, 1992). FS is a mathematic technique used herewith to establish the fuzzy membership function for each risk factor and FSE was then adopted to synthesize the effect of each risk factor and derive the overall risk level of PPP projects as a whole.

Factor Analysis: "FA is used to identify a relatively small number of factor groupings that can be used to represent relationships among sets of many inter-related variables" (Norusis, 1992). The technique was applied to the Delphi study to explore the factor groups that might exist among the risk factors in China's PPP projects. The number of factor groups required to represent that data set was determined by examining the total percentage of variance explained by each factor group (Chan et al., 2010). In this investigation, principal components analysis was used to identify the underlying factor groups because of its simplicity and distinctive characteristic of data-reduction capacity for factor group extraction (Chan et al., 2010). In order to obtain principal factor groups for a clearer image, factor extraction with varimax rotation and Kaiser Normalization were conducted through the SPSS FACTOR program.

Fuzzy Set: Since the criteria for risk evaluation are fuzzy in nature, this requires assessors' subjective value assessment (Cho et al., 2002). FS was therefore adopted in this study, which can be used to tackle ill-defined and complex problems due to incomplete and imprecise information that characterize the real risk level of risk factors (Zeng et al., 2007). In this study, a horizontal method was used for the determination of membership function of risk factors based on the results obtained from the two-round Delphi survey. A triangle function was used to represent the fuzzy membership functions of input variables of an enduser. The detailed process of the horizontal method used and triangle functions adopted will be discussed in the next section.

Fuzzy Synthetic Evaluation: FSE is a method to assess multiple criterion decisionmaking. It aims to provide a synthetic evaluation of an object relative to an objective in a fuzzy decision environment utilizing a number of factors ( $\mathrm{Li}$ et al., 2000). In this study, FSE is used to calculate the overall risk level of a PPP project. Based on Li et al. (2000) research, a multi-criterion evaluation model requires three basic elements:

1) A family of basic criteria/factors $\pi=\left\{f_{1}, f_{2}, \ldots, f_{m}\right\}$

2) A set of alternatives $E=\left\{e_{1}, e_{2}, \ldots, e_{n}\right\}$;

3) For every object $u \in U$, there is an evaluation matrix $R=\left(r_{i j}\right)_{m \times n}$. In the fuzzy environment, $r_{i j}$ is the degree to which alternative $e_{j}$ satisfies the criterion $f_{j}$. It is presented by the fuzzy membership function of alternative $e_{j}$ with respect to the criterion $f_{j}$.

With the preceding three elements, for a given $u \in U$, its evaluation result can be derived.

\section{PROCEDURES FOR DEVELOPING THE RISK EVALUATION MODEL}

Figure 1 shows that there are a total of eight steps to establish the computerized risk evaluation model. The first seven steps are used to develop the fuzzy risk evaluation model for PPP projects and step eight is used to transform the fuzzy evaluation algorithm into a computerized tool with the use of Visual Basic for Application (VBA). The following section will present the process in detail; and in the order of the (1) establishment of risk 
evaluation structure (from step 1 to step 4); (2) determination of weightings for each risk factor and risk criterion (step 5); (3) determination of fuzzy membership function for each risk factor (step 6); and (4) FSE for overall risk evaluation (step 7). Although the main objective of this paper is to report the computerized risk evaluation tool, the process of model development is also briefly presented for the ease of understanding the former.

\subsection{Establishing the risk evaluation structure (from Step 1 to Step 4)}

In this study, a total of 37 risk factors reported by $\mathrm{Xu}$ et al. (2010) were rated by the respondents in two rounds Delphi survey. Given the large number of risks related to PPP projects, it would be complex to evaluate them collectively, and difficult to draw meaningful conclusions. According to their risk impact rated by all of the 93 Delphi respondents, the top 17 risk factors with normalized values equal to or greater than 0.50 were considered as critical risk factors and were chosen for conducting the subsequent Factor Analysis (FA), which can further reduce the number of variables by combining two or more variables into a single group. For the selection of 17 critical risk factors please also refer to Xu et al. (2010). As the Pareto's principle states, for many events, $80 \%$ of effects come from $20 \%$ of the causes and the overall risk level of a specific project is usually dominated by critical risk factors (Iyer and Sagheer, 2010). Such selection also complies with the prerequisite of the Factor Analysis technique, which requires a ratio of 1:5 for variables to sample size (Lingard and Rowlinson, 2006). Various researchers have also followed the same procedures to meet the requirements of factor analysis (Martinez, 1994; Toor and Ogunlana, 2008). The Kendall's concordance analysis shows that in the two rounds of Delphi survey, both risk probability and risk severity were considered to be sufficiently consistent with $1 \%$ significance levels as shown in the Appendix 1. The results of appropriateness tests for Factor Analysis including (1) Bartlett test of sphericity and (2) Kaiser-Meyer-Olkin (KMO) test are also acceptable (Appendix 1).

Six factor groups were extracted after 5 iterations, which accounted for $66.26 \%$ of the variance in responses. The first three factor groups accounted for $14.9 \%, 14.5 \%$, and $12.3 \%$ of the variance, respectively. The remaining factor groups together accounted for $24.5 \%$ of the variance. Nearly all factor loadings were found to be above 0.5, with 12 of them being above 0.6 (Appendix 1). Based on the results, an assessment framework encompassing 17 risk factors (as indicators) was finally determined and serves as the basis for profiling and evaluating the risk level of PPP projects. The risk factors were classified into six categories based on the results of above Factor Analysis and structured into a three-level hierarchical structure as shown in Table 2. The first-level (top level) is the overall risk level. The second level represents the six critical criteria for depicting a PPP project's risk profile, namely (1) Macro Economic Risk (MER); (2) Construction and Operation Risk (COR); (3) Government Maturity Risk (GMR); (4) Market Environment Risk (MER); (5) Economic Viability Risk (EVR); and (6) Government Intervention Risk (GIR). The end user can also adjust the risk factors (indicators) based on specific project conditions. The risk factors presented in hierarchical, manageable, and defined format are beneficial to assist in their evaluation and communication (Iyer and Sagheer, 2010). The overall risk level can be represented and obtained through assessing the six critical risk criteria synthetically. Each of the second-level criteria has its sub-criteria, which are defined as the third-level indicators (i.e. risk factors). Risk evaluation of the hierarchical structure starts from the third level and continue to the first level. 
Table 2. Risk evaluation structure of PPP projects in China

\begin{tabular}{|c|c|c|c|c|}
\hline $\begin{array}{l}\text { A } \\
\text { Evaluation } \\
\text { goal }\end{array}$ & $\begin{array}{l}\text { B } \\
\text { Evaluation criteria }\end{array}$ & $\begin{array}{l}\text { C } \\
\text { Evaluation indicators (factors) }\end{array}$ & $\begin{array}{l}\text { Average relative } \\
\text { importance index }\end{array}$ & Rank \\
\hline \multirow{17}{*}{$\begin{array}{l}\text { Overall } \\
\text { risk level } \\
\text { of a specific } \\
\text { PPP } \\
\text { Project }\end{array}$} & \multirow{3}{*}{$\begin{array}{l}\text { B1 Macro economic } \\
\text { risk }\end{array}$} & C1 Foreign exchange fluctuation & 3.39 & 13 \\
\hline & & C2 Inflation & 3.39 & 14 \\
\hline & & C3 Interest rate fluctuation & 3.43 & 8 \\
\hline & \multirow{5}{*}{$\begin{array}{l}\text { B2 Construction } \\
\text { and operation risk }\end{array}$} & C4 Project/operation changes & 3.37 & 15 \\
\hline & & C5 Completion risk & 3.34 & 16 \\
\hline & & C6 Conflicting and imperfect contract & 3.42 & 9 \\
\hline & & C7 Price change & 3.29 & 17 \\
\hline & & C8 Operation cost overrun & 3.40 & 12 \\
\hline & \multirow{3}{*}{$\begin{array}{l}\text { B3 Government } \\
\text { maturity risk }\end{array}$} & C9 Government corruption & 3.62 & 3 \\
\hline & & C10 Imperfect law and supervision system & 3.56 & 5 \\
\hline & & C11 Poor public decision-making process & 3.64 & 2 \\
\hline & \multirow{3}{*}{$\begin{array}{l}\text { B4 Market } \\
\text { environment risk }\end{array}$} & C12 Financing risk & 3.62 & 4 \\
\hline & & C13 Change in market demand & 3.42 & 10 \\
\hline & & C14 Public credit & 3.49 & 6 \\
\hline & \multirow{2}{*}{$\begin{array}{l}\text { B5 Economic } \\
\text { viability risk }\end{array}$} & C15 Subjective project evaluation method & 3.46 & 7 \\
\hline & & $\begin{array}{l}\text { C16 Insufficient project finance } \\
\text { supervision }\end{array}$ & 3.41 & 11 \\
\hline & $\begin{array}{l}\text { B6 Government } \\
\text { intervention }\end{array}$ & C17 Government intervention & 3.91 & 1 \\
\hline
\end{tabular}

Note: the relative importance index is jointly determined by estimated probability of occurrence and severity of the risk consequence.

\subsection{Determining the fuzzy membership function for each risk factor (Step 5)}

It is well known that the evaluation of risk level for each risk factor is expected to be highly subjective and imprecise. The criteria are not clearly defined and are impractical to quantify. For example, what probability could be considered as "high", what severity could be regarded as "serious"? Similar to the estimation of probabilities in the probability theory, we can only obtain an approximate membership function for each risk factor because of our cognitive limitations as well as the fuzziness of the questions themselves (Lam et al., 2007). "The major distinction between random phenomena and fuzzy phenomena is that random events have clear and well-defined meaning, whereas a fuzzy concept does not have a precise extension because it is different to judge if an object belongs to the concept" (Tarighat and Miyamoto, 2009). Moreover, the probability and severity of each risk factor of PPP projects could change dynamically as a result of many uncertain variables, such as legal, macroeconomic, and natural conditions.

To tackle this problem, a fuzzy statistical approach was used to establish the fuzzy membership function. The fuzzy membership function for each risk factor comprises of two parts. Part one is formed based on the 93 Delphi experts' opinion obtained from the two-round Delphi survey, and part two is directly derived from end-user's own judgment according to their risk management capability, resources, and target project's risk profile. To assess the risk level of a specific PPP project, the Delphi expert's opinions are used to balance the enduser's judgment to achieve a relatively objective evaluation results. 
- Membership function of part one

The horizontal method was adopted to determine the membership function of part one. The underlying idea of the horizontal method is to gather information about membership values of the concept at some selected elements of the universal of discourse $R_{1}, R_{2}, \ldots, R n$ (Pedrycz, 2007). The method relies on experimental findings collected under the following scenario. If 100 questionnaires are collected, 2 out of 100 survey respondents regarded the risk probability of "foreign exchange fluctuation" as "very low", 8 survey respondents as "low", 45 survey respondents as "medium", 39 survey respondents as "high", and 6 survey respondents as "very high". Then the evaluation vector of membership function for probability of foreign exchange fluctuation can be denoted or represented by:

$$
\begin{aligned}
& \mathrm{C}_{\mathrm{p} 11}=\frac{0.02}{\text { verylow }}+\frac{0.08}{\text { low }}+\frac{0.45}{\text { medium }}+\frac{0.39}{\text { high }}+ \\
& \frac{0.06}{\text { veryhigh }}=\frac{0.02}{1}+\frac{0.08}{2}+\frac{0.45}{3}+ \\
& \frac{0.39}{4}+\frac{0.06}{5}
\end{aligned}
$$

which can also be re-written as $(0.02,0.08$, $0.45,0.39,0.06)$. Likewise, all other risk factors evaluation vectors of membership function can be obtained in a similar fashion. Pedrycz and Gomide (1998) regarded this as a very simple experiment, and when prudently arranged and completed, it can deliver reliable and significant estimates.

- Membership function of part two

The procedure for transforming input data so that they belong to a particular fuzzy subset is known as fuzzification (Lam et al., 2007). The linguistic input variables, denoted by Table 3 , are defined to describe the input variables to facilitate the building of fuzzy inference rules of end-user's judgment (Lam et al., 2007). The set is \{very low, low, medium, high, very high\}. The end-user can select the most appropriate option according to his risk management capability and resources. Triangle functions, based on experts' opinion, are used to represent the fuzzy membership functions of input variables of end-user's part as shown in Figure 2 and Table 4. Subsequently, the membership function for each risk indicator and risk criterion can then be determined by values in part one plus that in part two and summarized as shown in Tables 5 and 6.

Table 3. Terms for describing risk probability and risk severity

\begin{tabular}{ll}
\hline Risk probability & Description \\
\hline Very Low (VL) & Almost no possibility of occurring \\
Low (L) & Unlikely to occur \\
Medium (M) & Likely to occur \\
High (H) & Very likely to occur \\
Very High (VH) & almost certain to occur \\
\hline Risk severity & Description \\
\hline Very Low (VL) & No serious influence on the project \\
Low (L) & Slightly affect the project performance \\
Medium (M) & Moderately affect the project performance \\
High (H) & Significantly affect the project performance \\
Very High (VH) & Catastrophic, where the project would be aborted \\
\hline
\end{tabular}




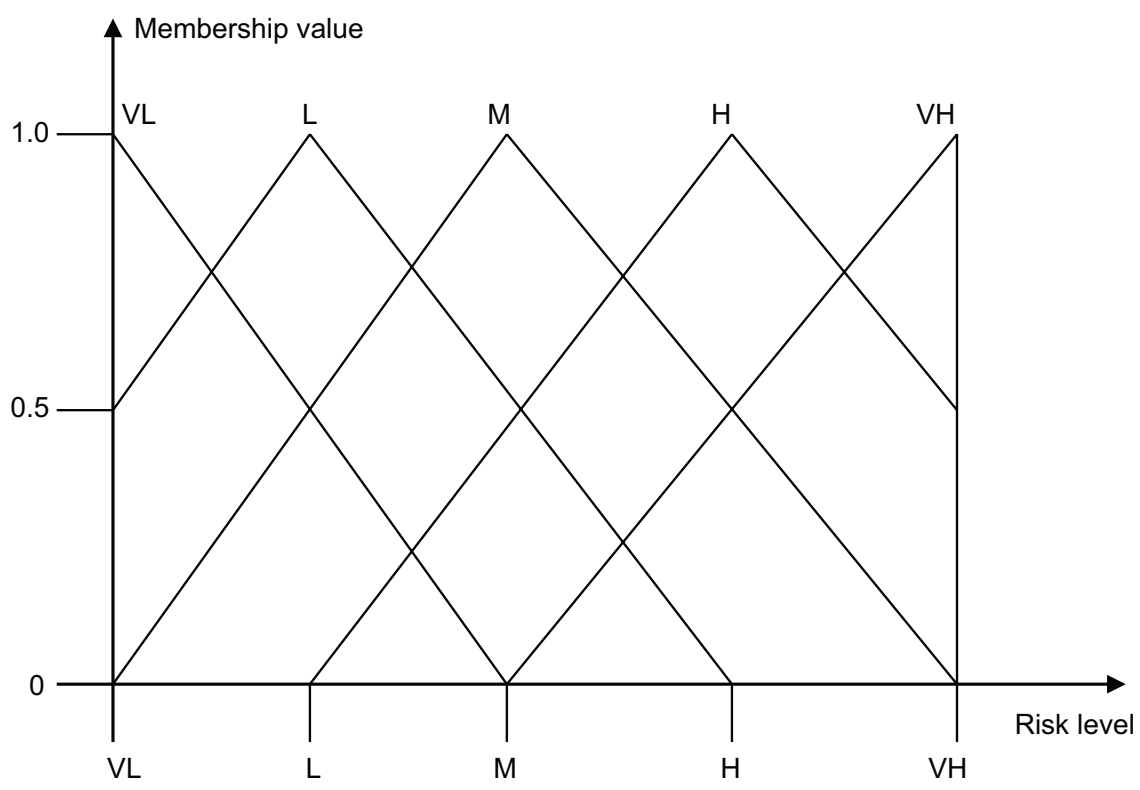

Figure 2. Membership functions of evaluation set

Table 4. Membership function for each possible risk perception value

\begin{tabular}{lll}
\hline Probability or severity & Degree of membership functions & Normalized degree of membership functions \\
\hline Very Low (VL) & $(1.0,0.5,0.0,0.0,0.0)$ & $(0.67,0.33,0.00,0.00,0.00)$ \\
Low (L) & $(0.5,1.0,0.5,0.0,0.0)$ & $(0.25,0.50,0.25,0.00,0.00)$ \\
Medium (M) & $(0.0,0.5,1.0,0.5,0.0)$ & $(0.00,0.25,0.50,0.25,0.00)$ \\
High (H) & $(0.0,0.0,0.5,1.0,0.5)$ & $(0.00,0.00,0.25,0.50,0.25)$ \\
Very High (VH) & $(0.0,0.0,0.0,0.5,1.0)$ & $(0.00,0.00,0.00,0.33,0.67)$ \\
\hline
\end{tabular}

Table 5. The weighting and membership function for possibility of each risk indicator and risk criterion

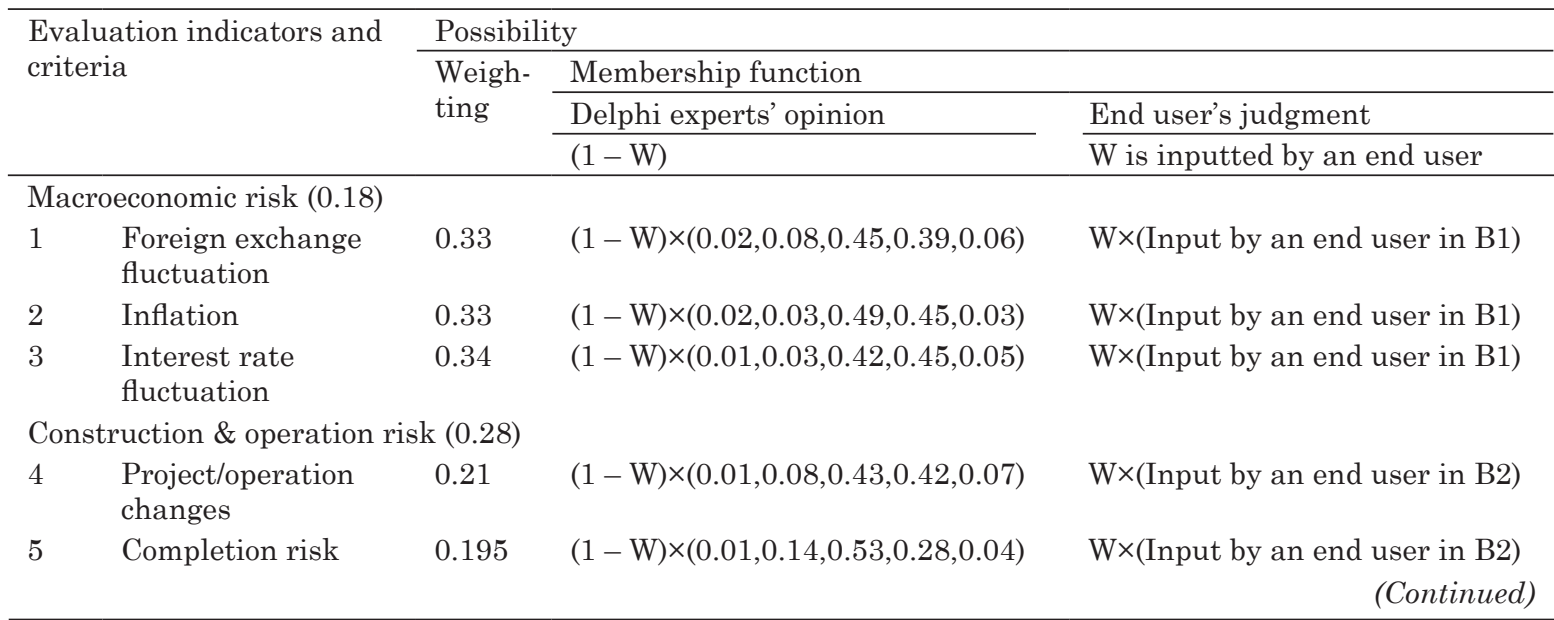




\begin{tabular}{|c|c|c|c|c|}
\hline \multirow{2}{*}{\multicolumn{2}{|c|}{$\begin{array}{l}\text { Evaluation indicators and } \\
\text { criteria }\end{array}$}} & \multicolumn{3}{|c|}{ Possibility } \\
\hline & & \multirow{3}{*}{$\begin{array}{l}\text { Weigh- } \\
\text { ting }\end{array}$} & \multicolumn{2}{|l|}{ Membership function } \\
\hline & & & Delphi experts' opinion & End user's judgment \\
\hline & & & $(1-W)$ & $\mathrm{W}$ is inputted by an end user \\
\hline \multicolumn{5}{|c|}{ (Continued) } \\
\hline 6 & $\begin{array}{l}\text { Conflicting or } \\
\text { imperfect contract }\end{array}$ & 0.205 & $(1-\mathrm{W}) \times(0.03,0.09,0.41,0.43,0.04)$ & $\mathrm{W} \times($ Input by an end user in B2) \\
\hline 7 & Price change & 0.19 & $(1-\mathrm{W}) \times(0.04,0.15,0.47,0.32,0.01)$ & $\mathrm{W} \times($ Input by an end user in B2) \\
\hline 8 & $\begin{array}{l}\text { Operation cost } \\
\text { overrun }\end{array}$ & 0.20 & $(1-\mathrm{W}) \times(0.01,0.12,0.50,0.34,0.03)$ & $\mathrm{W} \times($ Input by an end user in B2) \\
\hline \multicolumn{5}{|c|}{ Government maturity risk (0.19) } \\
\hline 9 & $\begin{array}{l}\text { Imperfect law and } \\
\text { supervision system }\end{array}$ & 0.33 & $(1-\mathrm{W}) \times(0.02,0.04,0.36,0.48,0.10)$ & $\mathrm{W} \times($ Input by an end user in B3) \\
\hline 10 & $\begin{array}{l}\text { Government } \\
\text { corruption }\end{array}$ & 0.33 & $(1-\mathrm{W}) \times(0.02,0.07,0.30,0.55,0.07)$ & $\mathrm{W} \times($ Input by an end user in B3) \\
\hline 11 & $\begin{array}{l}\text { Poor public decision- } \\
\text { making process }\end{array}$ & 0.34 & $(1-\mathrm{W}) \times(0.00,0.05,0.34,0.56,0.04)$ & $\mathrm{W} \times($ Input by an end user in B3) \\
\hline \multicolumn{5}{|c|}{ Market environment risk (0.17) } \\
\hline 12 & $\begin{array}{l}\text { Change in market } \\
\text { demand }\end{array}$ & 0.33 & $(1-\mathrm{W}) \times(0.02,0.11,0.51,0.33,0.03)$ & $\mathrm{W} \times($ Input by an end user in $\mathrm{B} 4)$ \\
\hline 13 & Public credit & 0.32 & $(1-\mathrm{W}) \times(0.05,0.09,0.48,0.32,0.05)$ & $\mathrm{W} \times($ Input by an end user in $\mathrm{B} 4)$ \\
\hline 14 & Financing risk & 0.35 & $(1-\mathrm{W}) \times(0.00,0.04,0.44,0.49,0.03)$ & $\mathrm{W} \times($ Input by an end user in B4) \\
\hline \multicolumn{5}{|c|}{ Economic viability risk $(0.11)$} \\
\hline 15 & $\begin{array}{l}\text { Subjective project } \\
\text { evaluation method }\end{array}$ & 0.515 & $(1-\mathrm{W}) \times(0.00,0.09,0.52,0.36,0.04)$ & $\mathrm{W} \times($ Input by an end user in B5) \\
\hline 16 & $\begin{array}{l}\text { Insufficient project } \\
\text { finance supervision }\end{array}$ & 0.485 & $(1-\mathrm{W}) \times(0.01,0.17,0.48,0.31,0.02)$ & $\mathrm{W} \times($ Input by an end user in B5) \\
\hline \multicolumn{5}{|c|}{ Government intervention (0.07) } \\
\hline 17 & $\begin{array}{l}\text { Government } \\
\text { intervention }\end{array}$ & 1 & $(1-\mathrm{W}) \times(0.00,0.01,0.20,0.66,0.13)$ & $\mathrm{W} \times($ Input by an end user in $\mathrm{B} 6)$ \\
\hline
\end{tabular}

Table 6. The weighting and membership function for severity of each risk indicator and risk criterion

\begin{tabular}{|c|c|c|c|c|}
\hline \multirow{2}{*}{\multicolumn{2}{|c|}{$\begin{array}{l}\text { Evaluation indicators and } \\
\text { criteria }\end{array}$}} & \multicolumn{3}{|c|}{ Severity } \\
\hline & & \multirow{3}{*}{$\begin{array}{l}\text { Weigh- } \\
\text { ting }\end{array}$} & \multicolumn{2}{|l|}{ Membership function } \\
\hline & & & Delphi experts' opinion & End user's judgment \\
\hline & & & $(1-W)$ & $\mathrm{W}$ is inputted by an end user \\
\hline \multicolumn{5}{|c|}{ Macroeconomic risk (0.17) } \\
\hline 1 & $\begin{array}{l}\text { Foreign exchange } \\
\text { fluctuation }\end{array}$ & 0.33 & $(1-\mathrm{W}) \times(0.00,0.08,0.48,0.40,0.03)$ & $\mathrm{W} \times($ Input by an end user in B1) \\
\hline 2 & Inflation & 0.33 & $(1-\mathrm{W}) \times(0.02,0.05,0.45,0.45,0.01)$ & $\mathrm{W} \times($ Input by an end user in B1) \\
\hline 3 & $\begin{array}{l}\text { Interest rate } \\
\text { fluctuation }\end{array}$ & 0.33 & $(1-\mathrm{W}) \times(0.00,0.10,0.43,0.46,0.01)$ & $\mathrm{W} \times($ Input by an end user in B1) \\
\hline \multicolumn{5}{|c|}{ Construction \& operation risk $(0.28)$} \\
\hline 4 & $\begin{array}{l}\text { Project/operation } \\
\text { changes }\end{array}$ & 0.19 & $(1-\mathrm{W}) \times(0.03,0.08,0.46,0.42,0.01)$ & $\mathrm{W} \times($ Input by an end user in $\mathrm{B} 2)$ \\
\hline 5 & Completion risk & 0.20 & $(1-\mathrm{W}) \times(0.00,0.08,0.42,0.44,0.07)$ & $\mathrm{W} \times($ Input by an end user in B2) \\
\hline 6 & $\begin{array}{l}\text { Conflicting or } \\
\text { imperfect contract }\end{array}$ & 0.20 & $(1-\mathrm{W}) \times(0.02,0.03,0.42,0.50,0.03)$ & $\mathrm{W} \times($ Input by an end user in B2) \\
\hline 7 & Price change & 0.20 & $(1-\mathrm{W}) \times(0.03,0.07,0.38,0.43,0.10)$ & $\mathrm{W} \times($ Input by an end user in B2) \\
\hline 8 & Operation cost overrun & 0.21 & $(1-\mathrm{W}) \times(0.02,0.05,0.33,0.55,0.04)$ & $\begin{array}{r}\mathrm{W} \times(\text { Input by an end user in B2) } \\
\text { (Continued) }\end{array}$ \\
\hline
\end{tabular}




\begin{tabular}{|c|c|c|c|}
\hline \multirow{4}{*}{$\begin{array}{l}\text { Evaluation indicators and } \\
\text { criteria }\end{array}$} & \multicolumn{3}{|l|}{ Severity } \\
\hline & \multirow{3}{*}{$\begin{array}{l}\text { Weigh- } \\
\text { ting }\end{array}$} & \multicolumn{2}{|l|}{ Membership function } \\
\hline & & Delphi experts' opinion & End user's judgment \\
\hline & & $(1-W)$ & $\mathrm{W}$ is inputted by an end user \\
\hline \multicolumn{4}{|l|}{ (Continued) } \\
\hline \multicolumn{4}{|c|}{ Government maturity risk (0.18) } \\
\hline $\begin{array}{ll}9 & \text { Imperfect law and } \\
\text { supervision system }\end{array}$ & 0.32 & $(1-W) \times(0.01,0.07,0.36,0.53,0.05)$ & $\mathrm{W} \times(\mathrm{Input}$ by an end user in B3) \\
\hline $10 \begin{array}{l}\text { Government } \\
\text { corruption }\end{array}$ & 0.34 & $(1-W) \times(0.00,0.08,0.29,0.52,0.12)$ & $\mathrm{W} \times($ Input by an end user in B3) \\
\hline $\begin{array}{l}11 \text { Poor public decision - } \\
\text { making process }\end{array}$ & 0.34 & $(1-W) \times(0.00,0.07,0.27,0.57,0.10)$ & $\mathrm{W} \times($ Input by an end user in B3) \\
\hline \multicolumn{4}{|c|}{ Market environment risk (0.18) } \\
\hline $\begin{array}{l}12 \text { Change in market } \\
\text { demand }\end{array}$ & 0.32 & $(1-W) \times(0.01,0.07,0.33,0.50,0.10)$ & $\mathrm{W} \times($ Input by an end user in B4) \\
\hline 13 Public credit & 0.34 & $(1-W) \times(0.03,0.03,0.24,0.54,0.16)$ & $\mathrm{W} \times(\mathrm{Input}$ by an end user in B4) \\
\hline 14 Financing risk & 0.34 & $(1-W) \times(0.02,0.02,0.22,0.68,0.06)$ & $\mathrm{W} \times($ Input by an end user in $\mathrm{B} 4)$ \\
\hline \multicolumn{4}{|l|}{ Economic viability risk (0.12) } \\
\hline $15 \begin{array}{l}\text { Subjective project } \\
\text { evaluation method }\end{array}$ & 0.49 & $(1-W) \times(0.00,0.04,0.39,0.53,0.04)$ & $\mathrm{W} \times($ Input by an end user in B5) \\
\hline 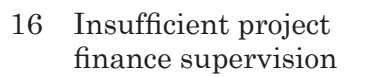 & 0.51 & $(1-\mathrm{W}) \times(0.00,0.04,0.30,0.58,0.08)$ & $\mathrm{W} \times($ Input by an end user in B5) \\
\hline \multicolumn{4}{|c|}{ Government intervention (0.07) } \\
\hline $17 \begin{array}{l}\text { Government } \\
\text { intervention }\end{array}$ & 1 & $(1-W) \times(0.00,0.01,0.22,0.61,0.16)$ & $\mathrm{W} \times($ Input by an end user in B6) \\
\hline
\end{tabular}

Note: W denotes the weighting of End user's judgment; (1-W) denotes the weighting of Delphi experts' opinion.

\subsection{Determining the weightings for each risk factor and risk criterion (Step 6)}

Each risk factor or risk criterion bears different impact on the overall risk level of PPP projects (Chen et al., 2008). The weighting reflects the relative strength or importance of the related risk factor (Chen et al., 2008). Weight synthesis provides a measure of combined effects from all the factors in question. Data collected from the Delphi questionnaire survey was analyzed using the mean value to determine the weighting of each risk factor and risk criterion. This technique was also used by Xu et al. (2010). Weightings for each risk factor and risk criterion are calculated by equations below.

$$
\begin{aligned}
& W=\left(W_{1}, W_{2}, \ldots, W_{m}\right) \\
& \mathrm{W}_{j}\left(\mathrm{M}_{1}, \ldots, \mathrm{M}_{m}\right)=\frac{\mathrm{M}_{j}}{\sum_{j=1}^{m} \mathrm{M}_{j}}
\end{aligned}
$$

$$
\begin{aligned}
& j=1,2, \ldots, m \\
& W_{j} \in[0,1] \quad W_{1}+W_{2}+\ldots W_{m}=1
\end{aligned}
$$

where: $\mathrm{W}$ represents the weighting of risk factors; $\mathrm{M}$ represents the mean value of risk impact.

After the above calculations, the weightings for each risk factor and risk criterion are summarized in Table 5 and 6.

\subsection{Fuzzy synthetic evaluation (Step 7)}

$$
\text { Model M }(\cdot, \oplus), \quad b_{j}=\min \left(1, \sum_{i=1}^{m} w_{i} \times c_{i j}\right)
$$

$\forall b j \in B$ is employed to evaluate the overall risk level of PPP projects ( $w i$ denotes the weighting of evaluation indicators or criteria. $c_{i j}$ denotes the membership function of evaluation indicators or criteria, b denotes membership function of risk criteria or PPP projects as 
a whole). The symbol $\oplus$ represents the summation of product of weighting and membership function. Model $\mathrm{M}(\cdot, \oplus)$ is suitable as all factors are considered and the weighting for each factor does not differ significantly (Lo, 1999). It should be noted that as both the w and $\mathrm{c}$ are normalized, and $\sum_{i=1}^{m} w_{i} \times c_{i j} \leq \underset{m}{1}$, therefore, model $\mathrm{M}(\cdot, \oplus)$ could be simplified as $b_{j}=\sum_{i=1}^{m} w_{i} \times c_{i j}$. Based on this calculation model, the membership function of risk possibility and risk severity for each risk criterion and final risk goal can be obtained. Finally, the risk impact can be determined by the product of risk possibility and risk severity via the formula as shown below.

\section{risk impact $=$}

$\sqrt{\text { risk possibility } \times \text { risk severity }}$

For the convenience of comparison among risk criteria and overall risk level between different PPP projects, the normalized membership function of risk impact can be further simplified through formula $B_{N}=\sum_{k=1}^{5} B_{k} \times K$ ( $B$ is membership function of risk criteria or PPP projects as a whole; $K$ is a constant) lastly, a constant can be obtained, which forms the basis for applications of risk evaluation results.

\section{APPLICATION OF THE EVALUATION RESULTS}

After following the above-mentioned 7 steps, the risk level of PPP project as a whole and the risk level of individual evaluation criterion of the project can be obtained. The results can be used (1) to help private investors and bankers identify appropriate PPP projects with the least risk for investment; and (2) find the most risky areas of a particular PPP project for effective risk response.
- Assisting a private investor or a banker in conducting risk assessment for investment

Risk evaluation is a pre-requisite procedure for investment decision-making. The investor needs to know a PPP project's overall risk level, including its construction and operation risk, government administration risk, market environment risk, economic viability risk, government intervention risk, and so on. In this regard, the end-user can input the information collected from the targeted PPP projects to calculate the overall risk level. And projects with lower overall risk index can be identified and short-listed for potential investment.

- Assisting the PPP practitioners' risk response

The risk index of evaluation criterion can be used to identify the most risky areas of a specific PPP project. This information can assist the PPP practitioners in adopting precise response measures to mitigate their risks and improve their risk management efficiency. It is beneficial to improve the project's financial performance, especially in China where the legal system for PPP projects has not been wellestablished.

\section{THE DESIGN OF A COMPUTERIZED RISK EVALUATION TOOL (STEP 8)}

For the convenience of end users, the automation process of the proposed risk evaluation model for PPP projects with the use of Visual Basic for Application (VBA) is developed. Although there are a number of programming languages available to program the risk evaluation model, including MATLAB, C language, and so on, VBA is chosen because it can operate under the environment of Microsoft Word. Therefore, there is no need for end-users to install additional new software program to their computers and they can easily learn the terms and syntax of the object model using the Macro Recorder. The computerized model can 
help reduce human and mathematical errors as data can be directly inputted by project participants and data analysis is then performed by the computerized procedure instead of the manual calculation.

The Risk Evaluation Model (REM) is operated through a user interface by clicking "Risk Evaluation" button as shown in Figure 3. A total of eight menus is displayed at the top of the first page, including: 1) Instruction; 2) MER; 3) COR; 4) GMR; 5) MER; 6) EVR; 7) GIR; and 8) Result. Menus 2 to 7 are used for data collection and menu 8 is designed for result output. The following sections will illustrate the usage of the risk evaluation tool in practice. The illustration focuses on three major areas, including: (1) Introduction; (2) Data Input; and (3) Result Output.

\subsection{Introduction of risk evaluation tool}

There is a plethora of useful information regarding the Risk Evaluation Model under "instruction" menu. They include: (1) procedures for developing the risk evaluation model; (2) the definition of each risk factor; and (3) calculation procedures of the risk evaluation model.
- Procedures for developing the risk evaluation model

This part defines the methodology and procedures of model development. It summarizes the research methods adopted in this study, including: (1) literature review; (2) Delphi questionnaire survey; (3) Factor Analysis; (4) Fuzzy Set Theory; and (5) Fuzzy Synthetic Evaluation, to the end-users for the ease of understanding the model development.

- Definition of risk factors

The interpretation of each risk indicator shows the full descriptions of the 17 evaluation indicators allowing the end-user to understand the risk definitions accurately. (For detailed risk definitions, please refer to the paper reported by Ke et al., 2009)

- Calculation Procedures of Risk Evaluation Model

There are a total of 4 steps to execute the computerized risk evaluation tool.

Step1: Assess the probability and severity of each risk factor with respect to the risk scenario.

Step 2: Repeat the same procedures until the assessment of all six risk criteria are finished.

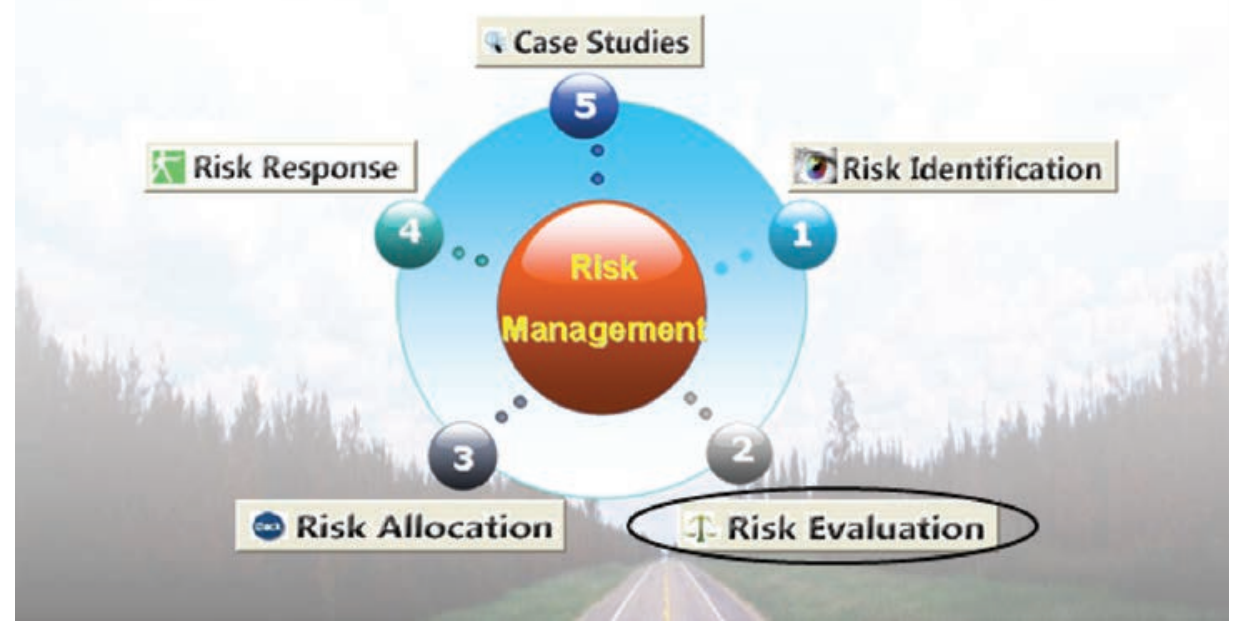

Figure 3. Interface of risk management software 
Step 3: Select the weighting for the enduser's own opinion, the program will automatically generate another value which represents the importance of the experts' opinion.

Step 4: Lastly, click the "Calculate" button. The final results which represent the overall risk level of a PPP project and the risk level of each risk criterion will be shown in the output box.

\subsection{Data input}

After reading the instructions of REM, the end-user can click the "Next" button to enter data into the data input menus by selecting the appropriate options. The system default value is "Medium". End-users can input their value of judgments based on the enterprise's resources, risk management capability and project's risk profile. The data input interface is shown in Figure 4. Moreover, it should be noted that

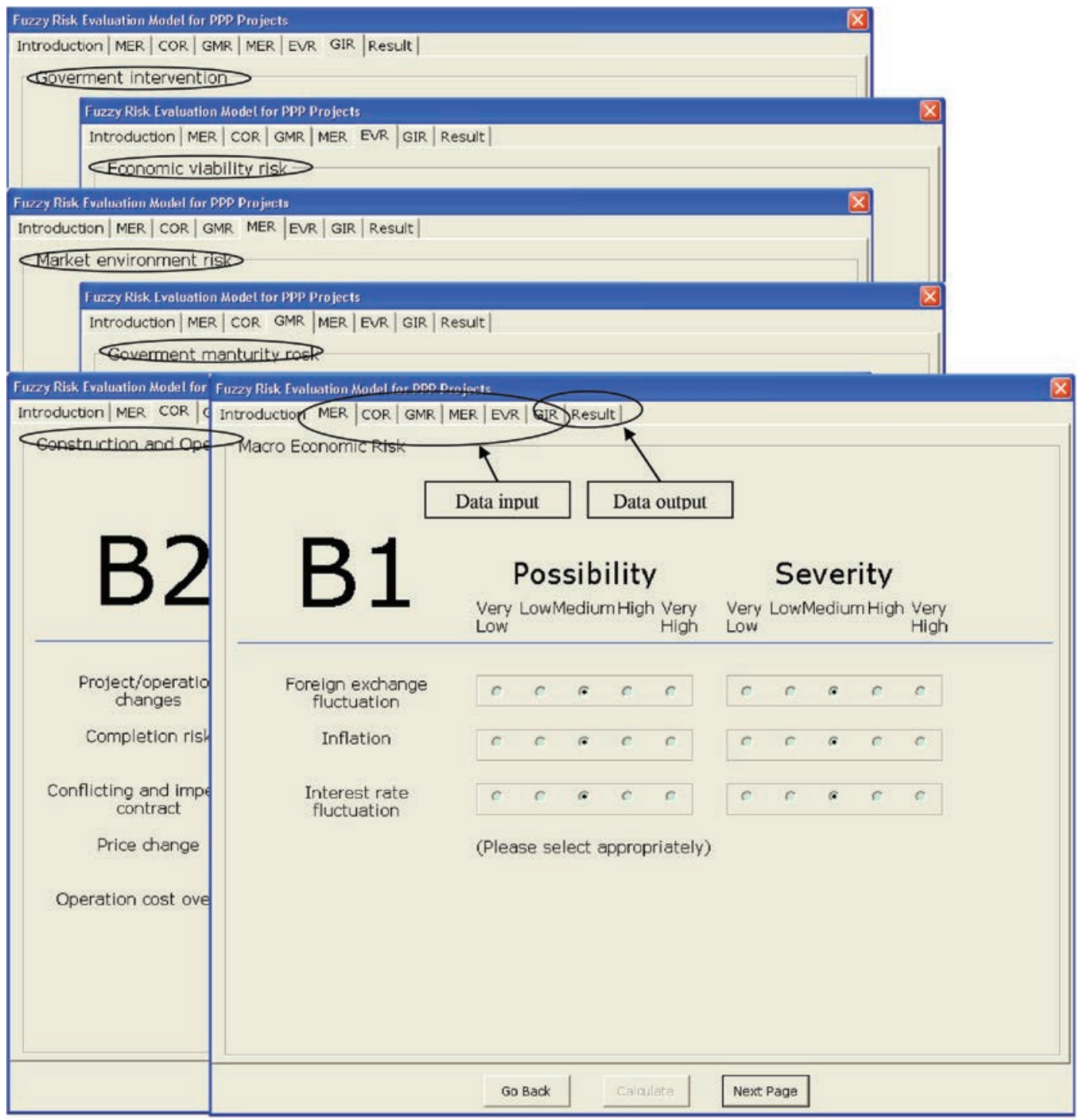

Figure 4. Data input format of the risk evaluation model 
before clicking the "Calculate" button, the endusers should select the appropriate weighting for their judgments. The expert's opinion is mainly used to balance the end-user's judgment to achieve a relatively objective evaluation results. The determination of weighting depends on end-user's experience and knowledge of risk evaluation of PPP projects. If the end-user are familiar with target PPP project and has much experience in risk management, he can assign a relatively smaller weighting to the Delphi expert's opinion, and vice versa. Another value that stands for the importance of the expert's opinion will be automatically generated.

\subsection{Result output for investment decision-making and risk response}

After entering the input data and clicking the "Calculate" button, the normalized value and histogram of the risk levels of evaluation criteria and PPP project as a whole will be generated as shown in Figure 5. The results allow risk managers, concessionaires, or government officers to measure the risk level of their current or potential PPP projects. The functions embodied in the Risk Evaluation Model will be demonstrated in the following case studies in a simulated project environment.

\section{AN ILLUSTRATIVE EXAMPLE APPLYING THE COMPUTERIZED MODEL FOR RISK EVALUATION IN A SIMULATED ENVIRONMENT}

This section illustrates a case study to present to the readers on how to use the model to make investment decisions and effective risk responses. Nan-tong Water Group (NWG) is a famous water company in China that holds a top position in PPP water business with a

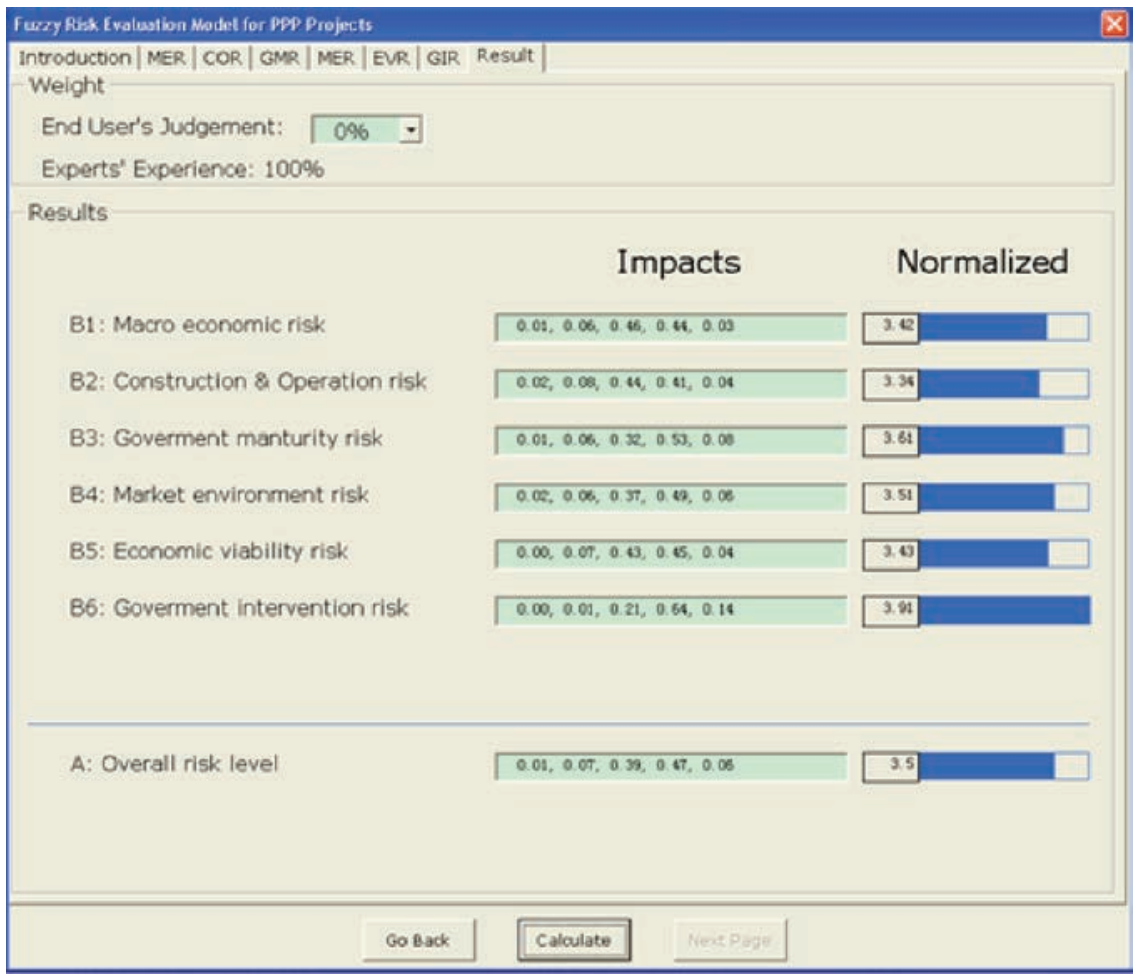

Figure 5. Data output format of the risk evaluation model 
focus on technology and management leadership. It has more than 20 water treatment and water supply plants nationwide, and over 160 employees. The NWG has built up a unique platform on which to support its customers with a range of services covering financing, design, construction, operation, and maintenance for water supply or sewage treatment. However, in recent practices, the NWG found that a lot of PPP projects were exposed to high risks, involving high cost overrun and even high failure rate. This signaled that it is necessary to strengthen risk evaluation and response of its PPP water projects in the process of bidding and project implementation. Therefore, NWG was keen to seek effective risk evaluation tools for improving its investment decision-making and risk response capability. According to the group's development plan, NWG will continue to perform expansion strategy in the next three to five years. It will hunt for appropriate water projects nationwide to further invest and enhance its market occupation rate through PPP procurement model. There are three water projects available for potential investment of NWG and are located in three different cities near Nantong city. The three projects have different local legal regulations, government regulations, and market risks. Their general information is summarized in Table 7.

To conduct this case study, the authors communicated several times with a project manager in charge of construction and operation management of a sewage treatment project in the suburb of Nantong city. The risk evaluation model was introduced to him in details, and the risk perception for each project was extracted based on his expert judgment and experience as shown in Table 8 (It should be note that the selection of risk possibility and severity based on a management team's judgment is better than that of a specific person's experience). The data was then inputted into the computerized risk evaluation model for overall risk index calculation and the result generated was compiled in Table 8. Project A's, B's, and C's overall risk indexes are 3.17, 3.54 and 3.10 respectively. It reveals that Project $\mathrm{C}$ (see Figure 6) was the best option for investment than project $\mathrm{A}$ and $\mathrm{B}$ from the standpoint of project risk. Moreover, for investment decision making, the investor also need to consider some other factors, such as Net Present Value (NPV), Internal return rate (IRR), and so on. By examining Project C's six risk criteria, it is indicated that market environment risk and government intervention risk are the most risky areas, scoring 3.55 and 3.45, respectively. Thus, potential risk response measures can be precisely designed and conducted to mitigate these most risky areas. Such as, the following measures 1 to 4 could be designed to cope with market environment risks, and the following measures 5 to 9 could be devised for handling government intervention risks.

1. Precautionary measures - conduct investigation to evade market risk. (Scrutinize environmental conditions such as, market tendency, price fluctuation tendency, international material, equipment, local currency's depreciation, geological condition, etc).

2. Transfer risks to the local government via government guarantees clause, compensation clause, or tariff and concession period adjustment clause.

3. Sign long-term purchase agreement with the government (adopt take-or-pay contract) and obtain price guarantee for the product or service from the government.

4. Obtain substantive preferential benefit from the government in the aspect of land, tax revenue, foreign exchange, raw material purchase, market supplies, and so on.

5. Define authority and responsibility in concession agreement and make clear guarantee clauses with the government to prevent from government intervention. 
Table 7. General information of the three selected PPP water projects

\begin{tabular}{llllll}
\hline Project name & Location & Water process load & $\begin{array}{l}\text { Concessionaire approx. cost } \\
\text { (RMB) (6.8 RMB=1USD) }\end{array}$ & $\begin{array}{l}\text { Concession } \\
\text { period (years) }\end{array}$ & $\begin{array}{l}\text { Type of } \\
\text { PPP }\end{array}$ \\
\hline Project A & Yancheng & 30 thousand Km/day & 70 million & 30 & BOT \\
Project B & Nanjing & 50 thousand Km/day & 110 million & 30 & BOT \\
Project C & Huaiying & 30 thousand Km/day & 55 million & 25 & BOT \\
\hline
\end{tabular}

Note: All three projects are under negotiation. Information provided by a project manager of Nan tong Water Group; BOT denotes Build/Operation/Transfer

Table 8. Risk perception for evaluation indicators of three selected PPP projects

\begin{tabular}{|c|c|c|c|c|c|c|c|}
\hline \multirow{2}{*}{\multicolumn{2}{|c|}{ Evaluation indicators and criteria }} & \multicolumn{2}{|l|}{ Project A } & \multicolumn{2}{|l|}{ Project B } & \multicolumn{2}{|l|}{ Project C } \\
\hline & & Possibility & Severity & Possibility & Severity & Possibility & Severity \\
\hline \multicolumn{8}{|c|}{ Macroeconomic risk } \\
\hline 1 & Foreign exchange fluctuation & VL & VL & M & $\mathrm{M}$ & VL & VL \\
\hline 2 & Inflation & VL & $\mathrm{H}$ & $\mathrm{VH}$ & $\mathrm{VH}$ & $\mathrm{L}$ & $\mathrm{H}$ \\
\hline 3 & Interest rate fluctuation & VH & M & M & $\mathrm{L}$ & VL & VL \\
\hline \multicolumn{8}{|c|}{ Construction \& operation risk } \\
\hline 4 & Project/operation changes & $\mathrm{L}$ & M & M & $\mathrm{H}$ & $\mathrm{L}$ & M \\
\hline 5 & Completion risk & M & M & $\mathrm{H}$ & $\mathrm{H}$ & $\mathrm{VH}$ & M \\
\hline 6 & $\begin{array}{l}\text { Conflicting or imperfect } \\
\text { contract }\end{array}$ & $\mathrm{L}$ & $\mathrm{L}$ & M & $\mathrm{M}$ & M & $\mathrm{L}$ \\
\hline 7 & Price change & VL & $\mathrm{VH}$ & $\mathrm{H}$ & $\mathrm{VH}$ & VL & VH \\
\hline 8 & Operation cost overrun & M & $\mathrm{L}$ & M & $\mathrm{L}$ & $\mathrm{L}$ & M \\
\hline \multicolumn{8}{|c|}{ Government maturity risk } \\
\hline 9 & $\begin{array}{l}\text { Imperfect law and } \\
\text { supervision system }\end{array}$ & VL & $\mathrm{L}$ & $\mathrm{H}$ & $\mathrm{H}$ & $\mathrm{L}$ & M \\
\hline 10 & Government corruption & M & $\mathrm{L}$ & $\mathrm{H}$ & $\mathrm{L}$ & $\mathrm{L}$ & $\mathrm{L}$ \\
\hline 11 & $\begin{array}{l}\text { Poor public decision-making } \\
\text { process }\end{array}$ & $\mathrm{VH}$ & $\mathrm{L}$ & $\mathrm{M}$ & $\mathrm{VH}$ & $\mathrm{M}$ & M \\
\hline \multicolumn{8}{|c|}{ Market environment risk } \\
\hline 12 & Change in market demand & VL & VH & $\mathrm{H}$ & $\mathrm{VH}$ & VL & VH \\
\hline 13 & Public credit & $\mathrm{H}$ & $\mathrm{H}$ & $\mathrm{VH}$ & M & $\mathrm{H}$ & M \\
\hline 14 & Financing risk & VH & $\mathrm{L}$ & $\mathrm{H}$ & $\mathrm{L}$ & $\mathrm{VH}$ & M \\
\hline \multicolumn{8}{|c|}{ Economic viability risk } \\
\hline 15 & $\begin{array}{l}\text { Subjective project evaluation } \\
\text { method }\end{array}$ & $\mathrm{H}$ & $\mathrm{L}$ & VH & $\mathrm{L}$ & $\mathrm{H}$ & $\mathrm{L}$ \\
\hline 16 & $\begin{array}{l}\text { Insufficient project finance } \\
\text { supervision }\end{array}$ & $\mathrm{L}$ & $\mathrm{L}$ & $\mathrm{VH}$ & $\mathrm{L}$ & $\mathrm{L}$ & M \\
\hline \multicolumn{8}{|c|}{ Government intervention } \\
\hline 17 & Government intervention & $\mathrm{VH}$ & $\mathrm{M}$ & $\mathrm{H}$ & $\mathrm{H}$ & $\mathrm{M}$ & $\mathrm{M}$ \\
\hline $\begin{array}{l}\text { Ove } \\
\text { the }\end{array}$ & $\begin{array}{l}\text { call risk level calculated by } \\
\text { cisk assessment model }\end{array}$ & 3.17 & & 3.54 & & 3.10 & \\
\hline & $\begin{array}{l}\text { sion-making (Experts' } \\
\text { ion: end-user's opinion }=50 \% \text { : }\end{array}$ & & & & & $x$ & \\
\hline
\end{tabular}


6. Develop and maintain good connections and relations with the local government authorities.

7. Obtain the letter of guarantee or consolatory letter from the higher levels of government.

8. Establish consortium with local renowned private enterprise, state-owned enterprise, and international corporation or government agencies.

9. Insurance for political risk.

If the above-mentioned measures can be implemented properly, the success of PPP projects can be ensured to some extent.

\section{CONCLUSIONS}

This paper presents a fuzzy risk evaluation model for assessing a PPP project's overall risk level, particularly with reference to the Chinese PPP industry. Risk evaluation factors (indicators) are structured into a three-level hierarchical structure, enabling the assessment of risk probability and risk severity to be undertaken at different levels. The model was primarily designed for two purposes, namely, for private investors or bankers to assess PPP projects' risk level for auxiliary investment decision-making and help PPP practitioners to identify their projects' most risky areas for effective risk management. The model calculation process is assisted with the computerized program designed by Visual Basic for Application for convenience use and precise calculation. The described model provides a tool to measure the risk level of PPP projects in quantitative terms. However, one limitation of this model is that the database of expert opinions is difficult to update as more expertise with relevant PPP projects is gained. Further research will focus on the design of the expert opinion updating system.

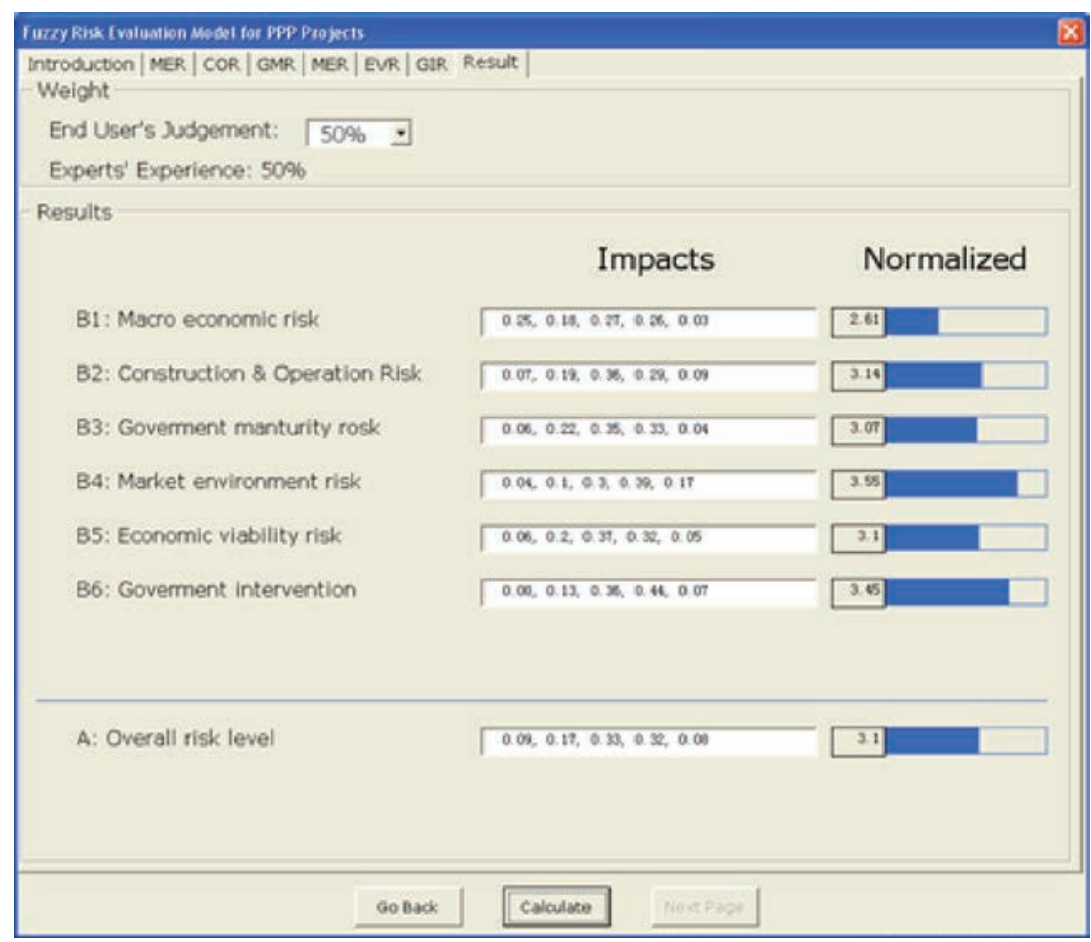

Figure 6. Risk evaluation result output of Project C 


\section{ACKNOWLEDGMENTS}

The work described in this paper has been supported by a joint grant from the Research Grants Council of the Hong Kong Special Administrative Region, China (Project No. N_PolyU 514/07) and the National Science Foundation Council of China Research Grant (Project No. 70731160634). The model presented in this paper also forms part of the broader research project entitled "Developing an Equitable Risk Sharing Mechanism for Public Private Partnership Projects in the People's Republic of China", from which other deliverables have been produced with different objectives/scopes but sharing common background of study and research methodology. Special gratitude is also extended to National Natural Science Foundation of China (Project No. 71101130).

\section{REFERENCES}

Asian Development Bank (2005) Technical assistance People's Republic of China: application of public-private partnerships in urban rail-based transportation project. Project Number 39527 , December 2005.

China Statistical Yearbook (2008) [Online] Available at: http://www.stats.gov.cn/tjsj/ndsj/2008/ indexch.htm.

Cho, H. N., Choi, H. H. and Kim, Y. B. (2002) A risk assessment methodology for incorporating uncertainties using fuzzy concepts, Reliability Engineering \& System Safety, 78(2), pp. 173-183. http://dx.doi.org/10.1016/S09518320(02)00158-8

Choi, H. H. and Mahadevan, S. (2008) Construction project risk assessment using existing database and project-specific information, Journal of Construction Engineering and Management-ASCE, 134(11), pp. 894-903. http://dx.doi.org/10.1061/ (ASCE)0733-9364(2008)134:11(894)

Chan, A. P. C., Lam, P. T. I., Chan, D. W. M., Cheung, E. and Ke, Y. J. (2010) Critical success factors for PPPs in infrastructure developments: Chinese perspective, Journal of Construction Engineering and Management-ASCE,
136(5), pp. 484-494. http://dx.doi.org/10.1061/ (ASCE)CO.1943-7862.0000152

Chen, J. S., Simpson, J. M., March, L. M., Cameron, I. D., Cumming, R. G., S Lord t. R., Seibel, M. J. and Sambrook, P. N. (2008) Fracture risk assessment in frail older people using clinical risk factors, Age and Ageing, 37(5), pp. 536541. http://dx.doi.org/10.1093/ageing/afn128 PMid:18541611

Ezell, B. C., Farr, J. V. and Wiese, I. (2000) Infrastructure risk analysis of municipal water distribution system, Journal of Infrastructure Systems-ASCE, 6(3), pp. 118-222. http://dx.doi. org/10.1061/(ASCE)1076-0342(2000)6:3(118)

Forbes, F., Smith, S. and Horner, M. (2008) Tools for selecting appropriate risk management techniques in the built environment, Construction Management and Economics, 26(11), pp. 1241-1250.

http://dx.doi.org/10.1080/01446190802468487

Iyer, K. C. and Sagheer, M. (2010) Hierarchical structuring of PPP risks using interpretative structural modeling, Journal of Construction Engineering and Management-ASCE, 136(2), pp. 151-159. http://dx.doi.org/10.1061/(ASCE) CO.1943-7862.0000127

Jablonowski, M. (1994) Fuzzy risk analysis using AI systems, AI Expert, December, pp. 34-38.

Ke, Y. J., Wang, S. Q., Chan, A. P. C. and Lam, P. T. I. (2010) Preferred risk allocation in China's public-private partnership (PPP) projects, International Journal of Project Management, 28(5), pp. 482-492.

http://dx.doi.org/10.1016/j.ijproman.2009.08.007

Lam, K. C., Wang, D., Lee, P. T. K. and Tsang, Y. T. (2007) Modelling risk allocation decision in construction contracts, International Journal of Project Management, 25(5), pp. 485-493.

http://dx.doi.org/10.1016/j.ijproman.2006.11.005

Lo, S. M. (1999) A fire safety assessment system for existing buildings, Fire Technology, 35(2), pp. 131-152.

http://dx.doi.org/10.1023/A:1015463821818

Lingard, H. and Rowlinson, S. (2006) Letter to the Editor, Construction Management and Economics, 24(11), pp. 1107-1109.

http://dx.doi.org/10.1080/01446190601001620

Li, H. X., Yen V. C. and Lee, E. S. (2000) Factor space theory in fuzzy information processingcomposition of states of factors and multifacto- 
rial decision making, Computer and Mathematics with Application, 39(1-2), pp. 245-265.

http://dx.doi.org/10.1016/S0898-1221(99)00327-2

Martinez, E. V. (1994) Avoiding large-scale information systems project failure: the importance of fundamentals, Project Management Journal, 25(2), pp. 17-25.

Nasirzadeh, F., Afshar, A., Khanzadi, M. and Howick, S. (2008) Integrating system dynamics and fuzzy logic modelling for construction risk management, Construction Management and Economics, 26(11), pp. 1197-1212. http://dx.doi.org/10.1080/01446190802459924

Norusis, M. J. (1992) SPSS for Windows, Professional statistics, Release 5, SPSS Inc., Chicago.

Pedrycz, W. and Gomide, F. (1998) An introduction to fuzzy sets: analysis and design. Massachusetts Institute of Technology.

Pedrycz, W. (2007) Granular computing - the emerging paradigm, Journal of Uncertain Systems, 1(1), pp. 38-61.

Skorupka, D. (2008) Identification and initial risk assessment of construction projects in Poland, Journal of Management in Engineering-ASCE, 24(3), pp. 120-127. http://dx.doi.org/10.1061/ (ASCE)0742-597X(2008)24:3(120)

Tarighat, A. and Miyamoto, A. (2009) Fuzzy concrete bridge deck condition rating method for practical bridge management system, Expert Systems with Applications, 36(10), pp. 1207712085. http://dx.doi.org/10.1016/j.eswa.2009.04.043

Tah, J. H. M. and Carr, V. (2000) A proposal for construction project risk assessment using fuzzy logic, Construction Management and Economics, 18(4), pp. 491-500.

http://dx.doi.org/10.1080/01446190050024905
Toor, S. R. and Ogunlana, S. O. (2008) Critical COMs of success in large-scale construction projects: evidence from Thailand construction industry, International Journal of Project Management, 26(4), pp. 420-430.

http://dx.doi.org/10.1016/j.ijproman.2007.08.003

Warszawski, A. and Sacks, R. (2004) Practical multifactor approach to evaluating risk of investment in engineering projects, Journal of Construction Engineering and Management-ASCE, 130(3), pp. 357-367. http://dx.doi.org/10.1061/ (ASCE)0733-9364(2004)130:3(357)

Winter, J. (1999) Risk analysis in construction. London: Baker \& McKenzie publications.

Xenidis, Y. and Angelides, D. (2005) The financial risks in build-operate-transfer projects, Construction Management and Economics, 23(4), pp. 431-441. http://dx.doi.org/10.1080/01446190500041552

Xu, Y., Yeung, J. F. Y., Chan, A. P. C., Chan, D. W. M., Wang, S. Q. and Ke, Y. (2010) Developing a risk assessment model for PPP projects in China - a fuzzy synthetic evaluation approach, $A u$ tomation in Construction, 19(7), pp. 929-943. http://dx.doi.org/10.1016/j.autcon.2010.06.006

Zeng, J. H., An, M. and Smith, N. J. (2007) Application of a fuzzy based decision making methodology to construction project risk assessment, International Journal of Project Management, 25(6), pp. 589-600. http://dx.doi.org/10.1016/j.ijproman.2007.02.006

Zayed, T., Amer, M. and Pan, J. (2008) Assessing risk and uncertainty inherent in Chinese highway projects using AHP, International Journal of Project Management, 26(4), pp. 408-419.

http://dx.doi.org/10.1016/j.ijproman.2007.05.012 
APPENDIX 1. Appropriateness tests and results of Factor analysis

\begin{tabular}{|c|c|c|c|c|c|c|c|}
\hline \multicolumn{2}{|c|}{ Item } & \multicolumn{4}{|c|}{ Kendall's coefficient of concordance (W) } & \multicolumn{2}{|c|}{ Significance level } \\
\hline & & \multicolumn{2}{|c|}{ Round one } & \multicolumn{2}{|c|}{$\%$ of improvement } & \multirow{2}{*}{$\begin{array}{l}\text { Round one } \\
.000\end{array}$} & \multirow{2}{*}{$\begin{array}{l}\text { Round two } \\
.000\end{array}$} \\
\hline \multicolumn{2}{|c|}{ Probability } & 0.183 & 0.251 & $37.2 \%$ & & & \\
\hline \multicolumn{2}{|c|}{ Severity } & 0.084 & 0.127 & $51.2 \%$ & & .000 & .000 \\
\hline \multicolumn{8}{|c|}{ KMO Value and Bartlett's Test of Sphericity } \\
\hline \multicolumn{6}{|c|}{ Kaiser-Meyer-Olkin Measure of Sampling Adequacy } & \multicolumn{2}{|l|}{0.621} \\
\hline \multirow{3}{*}{\multicolumn{3}{|c|}{ Bartlett's Test of Sphericity }} & \multicolumn{3}{|c|}{ Approx. Chi-Square } & \multicolumn{2}{|l|}{442.291} \\
\hline & & & \multicolumn{2}{|c|}{$\mathrm{Df}$} & & \multicolumn{2}{|l|}{136} \\
\hline & & & Sig. & & & \multicolumn{2}{|l|}{0.000} \\
\hline \multicolumn{8}{|c|}{ Factor Loading of Underlying Risk Factor } \\
\hline No. & Criti & actor $(\mathrm{Cl}$ & & $\begin{array}{l}\text { Factor } \\
\text { loading }\end{array}$ & Factor & & $\begin{array}{l}\text { Percentage } \\
\text { of variance } \\
\text { explained }\end{array}$ \\
\hline 1 & Fore & ange fluc & & 0.858 & \multirow{3}{*}{\multicolumn{2}{|c|}{ 1: Macroeconomic risk }} & 14.881 \\
\hline 2 & Inter & fluctuati & & 0.751 & & & \\
\hline 3 & Infla & & & 0.750 & & & \\
\hline 4 & Proje & tion cha & & 0.776 & \multirow{2}{*}{\multicolumn{2}{|c|}{$\begin{array}{l}\text { 2: Construction and operation } \\
\text { risk }\end{array}$}} & \multirow[t]{2}{*}{14.490} \\
\hline 5 & \multicolumn{3}{|c|}{ Completion risk } & 0.773 & & & \\
\hline 6 & \multicolumn{3}{|c|}{ Conflicting and imperfect contract } & 0.654 & & & \\
\hline 7 & \multicolumn{3}{|c|}{ Price change } & 0.521 & & & \\
\hline 8 & \multicolumn{3}{|c|}{ Operation cost overrun } & 0.469 & & & \\
\hline 9 & \multicolumn{3}{|c|}{ Government corruption } & 0.719 & & & \\
\hline 10 & \multicolumn{3}{|c|}{ Inadequate law and supervision system } & 0.692 & \multirow{2}{*}{\multicolumn{2}{|c|}{ 3: Government maturity risk }} & 12.339 \\
\hline 11 & \multicolumn{3}{|c|}{ Poor public decision-making process } & 0.585 & & & \\
\hline 12 & Fina & & & 0.762 & 4: Market & vironment risk & 8.827 \\
\hline 13 & Chan & arket den & & 0.586 & & & \\
\hline 14 & Publ & & & 0.520 & & & \\
\hline 15 & Subj & ject eva & hethod & 0.730 & 5: Econom & viability risk & 8.309 \\
\hline 16 & Insuf & roject fin & ervision & 0.654 & & & \\
\hline 17 & Gove & ntervent & & 0.862 & 6: Governr & nt intervention & 7.416 \\
\hline
\end{tabular}

Extraction method: Principal Component Analysis; Rotation method: Varimax with Kaiser Normalization; Rotation converged in 5 iterations. Adopted from Xu et al. (2010) 